\title{
FATORES de ESCOLHA dA CARREIRA dE AdMinistraÇão E dA INSTITUIÇÃO DE ENSINO
}

\section{FaCtors For Choosing The Business Management Profession And EDUCATION ENTITY}

\begin{abstract}
Sergio Paulo Muniz de Araujo (sergiopaulo3@ uol.com.br)
ESCOLA SUPERIOR DE ADMINISTRAÇÃO E GESTÃO

JoÃo MaURício GaMa BoAVENTURA

UNIVERSIDADE DE SÃO PAULO
\end{abstract}

\section{RENATO TELLES}

UNIVERSIDADE DE SÃo CAETANO DO SUL

\section{Jỗo Paulo Lara de Siqueira}

UNIVERSIDADE PAULISTA

\section{ANDRÉ RICARDO ROBIC \\ FundaÇÃo ARMANDO ÁlVAREs PENTEAdo}

\section{RESUMO}

O recrudescimento da competição e o crescimento de vagas não ocupadas caracterizam a situação de algumas instituições que oferecem o curso de Administração. Essa condição é agravada pela deficiência de dados sobre condicionantes para a escolha dessa carreira e de uma dada instituição de ensino. O presente trabalho, considerando esse cenário competitivo, se propôs desenvolver uma investigação dirigida ao mapeamento de aspectos associados à seleção de Administração como curso superior e à escolha da instituição de ensino superior como ofertante do serviço, focalizando a pesquisa na região do $\mathrm{ABC}$ Paulista. Numa primeira fase, de caráter exploratório, por meio de entrevistas com especialistas, levantaram-se motivos vinculados às escolhas. Seguiu-se uma investigação descritiva, com entrevistas a 1635 estudantes. Empregando-se instrumental multivariado, foram identificados cinco fatores para a opção pelo Curso de Administração: potencialidade, afinidade, continuidade, acessibilidade e familiaridade com a carreira. Para a escolha da instituição, quatro fatores foram levantados: infra-estrutura, imagem, indicação e acessibilidade, oferecendo-se dados efetivos para decisões de operação, de oferta de serviços e de comunicação junto às instituições.

Palavras-chave: estratégia; ensino; Administração; motivação. 


\section{ABSTRACT}

The intensification of competition and the growth of unoccupied positions characterize the situation of the institutions offering business administration degree. This condition is aggravated by the lack of information on students' motivation to choose such career and find the best relevant educational institution. This work purposes to develop a research considering the competitive scenario by mapping the aspectual issues regarding such choice, with focus on the research held in $A B C$ Paulista region. Initially, in an exploratory approach, experts were interviewed and the reasons of their options were pointed. In a second and descriptive phase, 1635 students were interviewed and the variables indicated by the experts were assessed. Making use of a multivariate tool, five factors were found to explain the choice for the Business Administration career: (potentiality, affinity, continuity, accessibility and familiarity with the career) and four factors were found to the choice of the school: Infrastructure, Image, Recommendation and Institution Accessibility, offering relevant data for operating decisions, provision of services and communication to the institutions.

Keywords: strategy; education; Management; motivation.

\section{INTRODUÇÃO}

O ensino superior brasileiro vem sendo objeto de "profundas e rápidas mudanças", segundo Araújo (2006, p.7), destacando-se a simplificação dos processos de credenciamento de mantenedoras e Instituições de Ensino Superior (IES) junto ao Ministério da Educação e Cultura (MEC). Esse contexto favoreceu um processo de oferta crescente de vagas no terceiro grau em função da expansão do número de instituições instaladas, em espaço de tempo relativamente reduzido.

Entre 1999 e 2004, segundo o Censo da Educação Superior (INEP/MEC; 2006), o número de IES autorizadas aumentou 106,89\%, com uma expansão média de $12,88 \%$ ao ano. No mesmo período, a ampliação de Cursos Superiores autorizados registrou uma taxa de crescimento de 168,26\%, ou seja, 17,88\% ao ano. Em decorrência disso, entre 2001 e 2004, a quantidade de vagas oferecidas subiu 199,01\%, ( $20,03 \%$ ao ano). No mesmo relatório, observa-se o crescimento relativo e absoluto dos cursos de Administração, caracterizado por uma evolução 
diferenciada dos demais, envolvendo ampliação na quantidade de autorizações de cursos, de vagas oferecidas e candidatos inscritos:

Aumento de Cursos Autorizados: ..... 7,90\% (2001) para 10,97\% (2004); Aumento de Vagas Oferecidas: ......... 2,80\% (2001) para 19,74\% (2004); Aumento de Total de Inscritos: .......... 9,66\% (2001) para 12,69\% (2004).

As taxas de ocupação de vagas, por outro lado, não vêm apresentando vigor comparável à oferta. No período de 1994 a 2006, a ocupação de bancos disponíveis nas IES evoluiu de 83,93\% para 56,13\%, sugerindo que o crescimento do número de vagas disponíveis vem perdendo sustentação na demanda por esse serviço. Por terem apresentado uma evolução de oferta mais acelerada, esse processo reflete-se nos cursos de Administração de forma mais crítica, como pode ser visto na Tabela 1.

Tabela 1: Número de Vagas Autorizadas e de Ingressantes nos Cursos Superiores de Administração

\begin{tabular}{cccc}
\hline \multirow{2}{*}{ Ano } & \multirow{2}{*}{ Vagas } & \multicolumn{2}{c}{ Ingressantes } \\
\cline { 3 - 4 } & & Quantidade & Ocupação $_{{ }^{\circ} \text { ano }}(\%)$ \\
\hline 2004 & 458.152 & 232.223 & $50,69 \%$ \\
\hline 2003 & 381.397 & 222.306 & $58,29 \%$ \\
\hline 2002 & 313.423 & 204.045 & $65,10 \%$ \\
\hline 2001 & 232.537 & 167.132 & $71,87 \%$ \\
\hline 2000 & 179.929 & 129.469 & $71,96 \%$ \\
\hline 1999 & 123.393 & 101.009 & $81,86 \%$ \\
\hline 1998 & 99.338 & 86.173 & $86,75 \%$ \\
\hline
\end{tabular}

Fonte: INEP/MEC - Censo da Educação Superior (2006).

De acordo com os dados apresentadas na Tabela 1, pode-se perceber que um processo de intensificação competitiva encontra-se em curso entre as instituições de ensino superior que oferecem vagas para os cursos de Administração. Esse quadro, que se agrava para o lado da oferta de cursos em Administração, tende a provocar reorientações de estratégia e operação, mas impõe a priori uma compreensão mais abrangente e precisa dos fatores determinantes e condicionantes da opção de estudantes secundaristas pela carreira em Administração.

A situação na qual se encontram as instituições que oferecem o curso de Administração caracteriza-se pela deficiência de informações sobre condicionantes ou determinantes da escolha por essa carreira. O presente trabalho, considerando essa condição e o contexto de recrudescimento do cenário competitivo das instituições de ensino 
superior que oferecem vagas para graduação em Administração, se propõe a levantar e compreender os aspectos associados à opção da Administração como curso superior e à escolha da IES para sua realização. $\mathrm{O}$ estudo, em função de condicionantes de acesso, focalizou a região do $\mathrm{ABC}$ Paulista.

O presente trabalho adotou como condições de contorno para seu desenvolvimento, fronteiras espaciais e temporais de focalização da pesquisa, delimitando domínio de acesso e coleta de dados. A pesquisa foi realizada no primeiro semestre de 2006, com estudantes do curso superior de Administração na região do ABC Paulista. Com o propósito de contextualização do ambiente, elaborou-se uma caracterização descritiva da situação na região e no período à época da pesquisa, sem a pretensão de sugerir ou reconhecer vinculação direta com resultados obtidos. Nesse sentido, não se pode admitir sem ressalvas que elementos ou variáveis do cenário em que se desenvolveu a coleta de dados, permaneçam ou tenham preservado a configuração.

\section{REFERENCIAL TEÓRICO}

A constituição de uma plataforma conceitual de referência para o presente trabalho foi composta por revisão do processo de compra, focalizando o envolvimento do consumidor, a incerteza da compra de serviços, considerando o pacote de valor (característico do produto ensino) e a busca de informações do consumidor de ensino, levantando-se potenciais atributos considerados pelo mercado-alvo.

\section{Entre a intenção de compra e a decisão de compra}

Autores referenciais em comportamento do consumidor, como Engel, Blackwell e Miniard (2001) e Sheth, Mittal e Newman (2001), entendem a decisão de compra como um processo de solução de problema. Para satisfazer determinada necessidade, o consumidor desenvolve o desejo por algum produto que, na sua percepção, oferece valor comparativamente superior em relação a alternativas de compra. $\mathrm{O}$ desejo por um produto, desse modo, é o resultado de uma apreciação avaliativa orientada para a seleção do produto, descrita, em geral, como composta pelas etapas: (1) reconhecimento do problema, (2) busca de informações, (3) processo de avaliação das alternativas de pré-compra e (4) a compra.

As transformações em curso no mercado (como expansão do número de organizações oferecendo bens e serviços) e em relação ao 
consumidor (como ampliação do acesso à informação) levaram as empresas a priorizar a compreensão do comportamento do consumidor, segundo Engel, Blackwell e Miniard (2001), ou seja, o entendimento do processo de decisão de uso de seus recursos, envolvendo dinheiro, tempo e esforço, na aquisição de produtos de consumo.

$\mathrm{Na}$ abordagem do comportamento do consumidor, em especial, deve ser levado em conta o intervalo entre o momento em que se define a intenção e o momento em que se dá a decisão de compra. Um aspecto particularmente relevante nesse processo é o do envolvimento do consumidor com a compra. Duas perspectivas sobre esse envolvimento devem ser reconhecidas: (1) ser uma condição influenciável por atitude/postura de outras pessoas e por fatores situacionais imprevistos e (2) constituir uma situação sensível à percepção de risco associado ao processo de compra, conforme Jacob e Kaplan (1972).

Outro aspecto, observado por Espartel, Trez e Fonseca (2001, p.4), é a importância do envolvimento desse consumidor na solução desenvolvida após o reconhecimento do problema (no processo de decisão de compra), em situações de compra com elevado grau de complexidade. A opção por um curso universitário, segundo o que se infere de Kotler e Fox (1994), compreende uma decisão de compra com elevado grau de complexidade e, dessa forma, associada a alto grau de envolvimento do consumidor.

\section{A Incerteza inerente à Compra de Serviços}

O ensino é tipicamente uma prestação de serviço, sendo consenso na literatura e assim descrito por autores como Lovelock e Wirtz (2006), Hoffman (2003), Zeithaml e Bitner (2003) e Bateson e Hoffman (2001). Uma característica peculiar do produto serviço reside no fato de que o benefício (associado à satisfação de uma necessidade) é oferecido e percebido por meio de um resultado apreendido pelo usuário e, nessa medida, por meio de uma experiência interativa que envolve o consumidor com mais ou menos intensidade, conforme Hoffman (2003).

Frequentemente, textos básicos de Marketing, como os citados, apresentam as quatro características de serviços: intangibilidade, variedade, inseparabilidade e perecibilidade. A intangibilidade é determinante para uma questão fundamental na avaliação de compra: a impossibilidade de avaliação antecipada do produto, assim como a inviabilidade de devolução dos resultados entregues. Nesse sentido, a compra de um serviço, em comparação à compra de um bem, envolve um 
grau de incerteza superior na medida em que a decisão de compra tem de se basear em credibilidade no fornecedor. Dessa forma a conjugação de uma compra com alto envolvimento de um produto intangível, e, portanto, associado à incerteza da efetiva configuração do benefício recebido, sugere que a escolha por uma carreira e por uma instituição de ensino se constituem numa resultante da combinação de diferentes variáveis. Deve-se reconhecer, também, que o ensino superior corresponde a um "pacote de valor", ou seja, "um conjunto de bens e experiências que constituem uma oferta única", segundo Albrecht (1992), e que esse conceito compreende o produto como uma composição de bens e serviços. Sob essa perspectiva, determinados atributos da oferta de ensino superior são tangíveis, como infra-estrutura e localização. Portanto, informações sobre a importância relativa dessas características para o mercado-alvo constituem dado relevante para a definição de estratégias de expansão de valor na percepção de consumidores.

\section{Comportamento do consumidor em relação ao produto ensino}

O interesse por acesso a conhecimento e, por consequência, a procura e a busca por fornecedores desse produto não é um fenômeno atual. Na Grécia antiga, professores viajavam oferecendo serviços, sustentando-se com o pagamento de seus estudantes, segundo Platão (1980), no texto "Apologia a Sócrates". No século XIX, faculdades recém criadas nos Estados Unidos, frequentemente, se viam pressionadas a divulgar as vantagens da formação universitária para a população, majoritariamente rural, lançando mão de folhetos e oferecendo bolsas de estudo. Singer (2001) afirma que após a Segunda Guerra, a ampliação do número de universidades e instituições, oferecendo ensino superior, nos EUA, em um contexto de disponibilidade de importante apoio financeiro e programas de empréstimos financiados pelo Governo induziu um fluxo crescente de egressos do nível médio na educação superior. Nesse momento, em função da mudança de relação entre oferta e demanda de vagas, passa a ser necessário um departamento de admissões responsável pela seleção de candidatos.

Nos anos 70, o cenário competitivo das instituições americanas de ensino superior inicia uma era de recrudescimento, afirmam Kotler e Fox (1994), impondo a necessidade da adoção de estratégias institucionais de atração de candidatos. Mais recentemente, no Reino Unido, segundo esses autores, as instituições reconheceram a mesma necessidade e passaram a 
desenvolver ações, progressivamente mais agressivas, de comunicação e acesso a candidatos,

Os atributos mais frequentemente considerados em um curso universitário americano, conforme Kotler e Fox (1994) são: (1) reputação acadêmica; (2) custo; (3) localização do campus; (4) distância de casa; (5) extensão do campus; (6) convívio social; (7) aparência física do campus; (8) moradia (residência no campus); e (9) colocação no mercado de trabalho.

Verificou-se importante variação sobre a relevância de cada atributo para diferentes estudantes, assim como sua importância relativa para os candidatos. A oferta, nesse sentido, deve ser ajustada para que forneça a captação ótima possível de alunos. Essa perspectiva remete à necessidade de gestão do mercado ao longo do tempo, procurando-se aferir e identificar mudanças de padrões na avaliação das características oferecidas e expectativas emergentes de candidatos ao ensino superior. Segundo Murphy (1981), entre as características buscadas num curso universitário, os estudantes americanos em instituições de nível superior) referem-se com maior frequência a: (1) reputação acadêmica; (2) custo; (3) localização do campus; (4) distância de casa; (5) extensão do campus; (6) convívio social; (7) aparência física do campus; e (8) colocação no mercado de trabalho. Convergindo com as afirmações de Kotler e Fox (1994), Murphy (1981) verificou variações significativas entre estudantes sobre a relevância e a importância relativa de cada atributo. Em relação a essa dispersão de resultados de percepção, Kotler e Fox (1994) defendem que as preferências dos consumidores educacionais são frequentemente aglomeradas, pois essas preferências não estão ligadas a programas sob medida, e, em geral, esses consumidores ficam mais satisfeitos com programas mais baratos para perfis mais amplos.

Estudo semelhante, realizado no Brasil por Moraes et al (2006), com estudantes de educação continuada, não ofereceu conclusões análogas às das pesquisas americanas, apresentando alguns atributos comparáveis (como prestígio da instituição) e outros distintos (como prestígio dos professores). A diferença entre as expectativas e o rol de atributos relevantes pode ser associada a variáveis como idade, cultura e estágio de ciclo de vida; e podem decorrer também de aspectos e condicionantes específicos de contexto histórico e geográfico. 


\section{Decisão e escolha de carreira}

A opção por uma carreira relacionada com a escolha de um curso de graduação está ligada a diferentes teorias na literatura, impondo uma arbitragem sobre construto ou buscando uma conjugação sustentável entre esses construtos. O trabalho de Crites (1974), nesse sentido, oferece uma perspectiva estruturada e articulada sobre o tema, razão de seu uso frequente em estudos sobre esse assunto. Esse autor desenvolveu uma classificação sobre abordagens teóricas, agrupando-as, segundo a origem de suas bases de sustentação, quais sejam: psicológicas, não-psicológicas (sociológicas e econômicas) e gerais (interdisciplinares) (CRITES, 1974, p.95).

As teorias psicológicas, de forma geral, trabalham com a ideia de escolha de carreira associada a condicionantes pessoais, desdobrados de processos históricos particulares de construção/desconstrução das condições individuais da formação dos indivíduos, ligados a características imanentes das pessoas e das situações ambientais específicas (cultura, família, recursos etc.) (SUPER; BOHN Jr., 1980; HOLLAND, 1975). As teorias não-psicológicas (sociológicas e econômicas) focalizam, com maior importância, condicionantes externos ao indivíduo na orientação de sua escolha de curso, particularmente as variáveis de ambiente. Essas variáveis de ambiente são religião, classe sócio-econômica, acesso a oportunidades, configuração cultural dos meios de convívio social, mercado de profissões, taxa de crescimento populacional e evolução tecnológica, entre outras. (FOLMERJOHNSON, 2000; CHANLAT, 1995; SUPER; BOHN Jr., 1980; PIMENTA, 1979). As teorias gerais se propõem a construir composições sustentáveis entre diferentes perspectivas, via de regra caracterizadas pelo equilíbrio atribuído a variáveis individuais e ambientais (BOMTEMPO et al, 2007; BLAU et al, 1968).

Investigações mais recentes, e caracterizadas por maior pragmatismo, indicam que as razões para a seleção da carreira universitária guardam importante semelhança, independente de curso ou espaço de atuação (SILVA; MACHADO, 2007, GODOY; SANTOS; MOURA， 2001; OLIVEIRA， 2001; FOLMER-JOHNSON， 2000; SOARES-LUCCHIARI，1997; WHITAKER， 1985). Nesse sentido, poderiam ser destacadas como dimensões potencialmente intervenientes na escolha de curso universitário: (I) Influência da família e de grupos de convívio; (II) Vocação ou apelo pessoal; (III) Mercado de trabalho; (IV) Prestígio da carreira; (V) Potencial de sucesso profissional; (VI) 
Comunicação veiculada; (VII) Capacidade de acesso (econômica, geográfica, cultural etc.); (VII) Aperfeiçoamento/especialização de competências.

\section{Decisões sobre carreira e instituição: busca de informações}

O procedimento de compra, a partir de uma abordagem que considera a racionalidade do consumidor, admite a existência de um processo de natureza complexa na mente do consumidor que pode ser composto por quatro etapas consecutivas: (1) reconhecimento do problema, (2) busca de informações, (3) avaliação de alternativas e (4) decisão de compra.

A busca de informações é a fase em que ações estratégicas de organizações que ofertam alternativas de solução para os problemas reconhecidos pelo mercado-alvo passam a apresentar impacto na consideração e escolha do consumidor. Kotler e Fox (1994) entendem que as questões que mais interessam às instituições de ensino, com relação ao momento em que os alunos buscam informações sobre as escolas, são:

1. Volume de informações que os consumidores coletam antes de decidir.

2. Fontes de informação usadas e influências relativas sobre os consumidores.

As fontes de informação apresentadas no Quadro 1, envolvendo curso/instituição, podem ser classificadas em quatro grupos, segundo os autores:

Quadro 1: Fontes de Informação de Consumidores Potenciais no Ensino Superior

\begin{tabular}{ccc}
\hline $\begin{array}{c}\text { Fontes de } \\
\text { Informação }\end{array}$ & $\begin{array}{c}\text { Não Controlada } \\
\text { pela Instituição }\end{array}$ & $\begin{array}{c}\text { Controlada } \\
\text { pela Instituição }\end{array}$ \\
\hline Pessoal & $\begin{array}{c}\text { Família, amigos, } \\
\text { colegas e conhecidos. }\end{array}$ & Vendedores \\
\hline Impessoal & $\begin{array}{c}\text { Mídia de Massa, } \\
\text { ocorrências naturais. }\end{array}$ & Anúncios e catálogos \\
\hline
\end{tabular}

Fonte: Adaptado de Kotler e Fox (1994).

A coleta de informações no mercado de ensino pode ser representada pela Figura 1, segundo proposta de Ihlanfeldt (1980), que desenvolveu seu modelo pesquisando o mercado norte-americano. Nessa figura, as linhas contínuas indicam influência direta no processo de escolha da instituição e as linhas segmentadas indicam influência indireta. 
Figura 1: Influência de Fontes de Informação na Decisão de Escolha de Instituição por Estudantes (nos EUA)

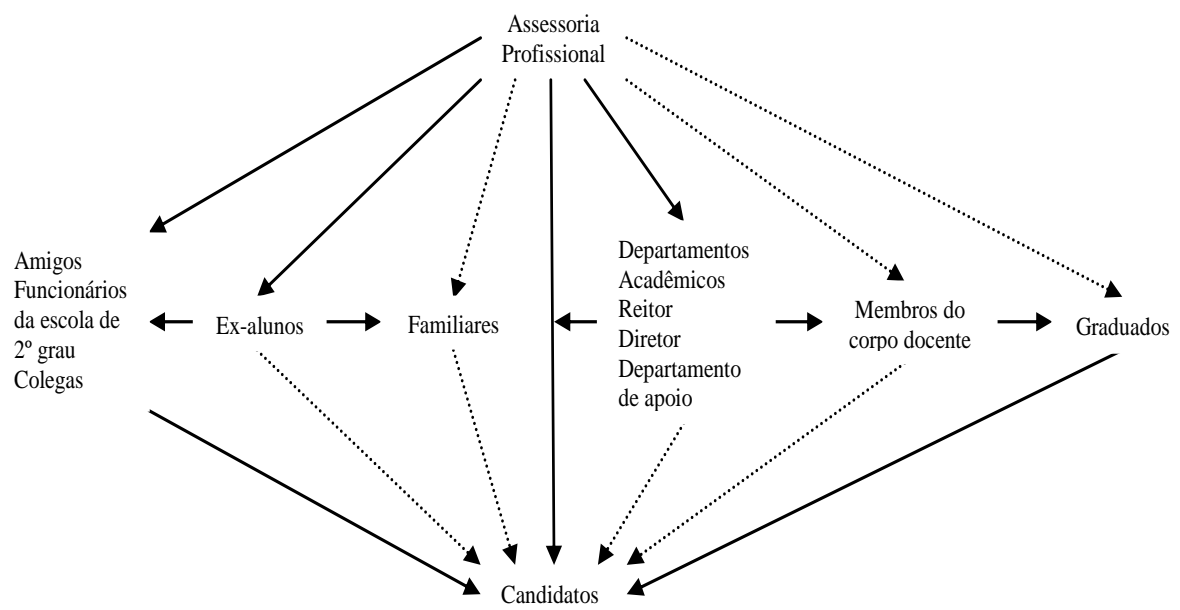

Fonte: Ihlanfeldt (1980).

Carvalho e Berbel (2000) observam que o produto que uma escola oferece não é percebido de imediato, ou seja, o valor se manifesta ao longo de anos, tendendo a se preservar. As instituições de ensino vendem promessas de entrega, passíveis de avaliação no futuro. Essa configuração do processo implica dificuldades de acesso e intervenção, tornando sua apreensão um processo em geral associado a premissas e ressalvas.

Sobre a busca de informações sobre alternativas de ensino superior, Oliveira (2004), em artigo publicado no jornal Folha de São Paulo, afirma que, no Brasil, o segmento de cursos de ensino superior padece de uma falha comum a outros mercados: nem sempre os participantes do mercado possuem o mesmo volume/qualidade de informações sobre instituições e cursos. Frequentemente, os consumidores têm de se guiar pela reputação dos fornecedores. Muitas vezes, a escolha da faculdade é feita baseando-se em opiniões de amigos, parentes e, eventualmente, profissionais. As instituições mais conhecidas obtêm um prêmio de reputação e tendem a se acomodar, tornando indistintas as escolas sérias de outras menos reconhecidas.

Os alunos poderiam estar dispostos a pagar mais para fazer um curso conceituado ou considerar um programa menos reconhecido em função de menor custo, mas as razões consideradas não são suficientemente conhecidas. A seleção de uma instituição em detrimento de outras pode estar associada a variadas motivações como: (a) pais terem 
estudado numa dada escola, (b) impressão positiva de um profissional vinculado a uma dada faculdade e (c) opiniões de pessoas de reconhecida autoridade.

\section{Método de PeSQuisa}

Este estudo foi dividido em duas fases: (1) uma exploratória, em que se buscou identificar variáveis a serem avaliadas, e (2) uma descritiva, na qual se avaliou o comportamento das variáveis, identificadas na fase anterior, para a amostra da população de interesse do estudo.

$\mathrm{Na}$ fase exploratória, a pesquisa exploratória foi realizada com indivíduos que potencialmente reuniam informações sobre o tema e se dispunham a participar do estudo, não partindo de um delineamento estruturado. $\mathrm{O}$ método qualitativo é particularmente recomendado na investigação exploratória, conforme Terence e Escrivão (2006), no sentido de possibilitar e estimular o "desenvolvimento de novas compreensões sobre a variedade e a profundidade dos fenômenos sociais". A configuração da investigação, nessa fase, pode ser tipificada como qualitativa e, de acordo com Gordon e Langmaid (1988), admitem pequenas amostras (sem a necessidade de representatividade). Nessa fase foram entrevistados oito diretores, cinco coordenadores e quatro orientadores de escolas de segundo grau (públicas e privadas), seis orientadores vocacionais de cursos pré-vestibulares, 23 pais (mãe ou pai) de aluno do nível médio e 56 estudantes de nível médio. Todos os respondentes foram entrevistados pelo mesmo pesquisador e solicitados a indicar motivos influenciadores (sem informações de partida para escolha ou seleção) e, para cada um desses motivos, atribuir um grau de importância numa escala de zero a cinco (zero para nenhuma importância e cinco para máxima importância). $\mathrm{O}$ resultado se constitui em um elenco de razões para a escolha de um curso universitário, não se restringindo ao curso de Administração.

$\mathrm{Na}$ fase descritiva, o rol de razões para a escolha de um curso universitário ofereceu a base de referência no desenvolvimento de um estudo descritivo junto aos estudantes de primeiro ano de Administração, orientado para a identificação da importância de cada um dos motivos influenciadores (elencados na etapa anterior) na decisão para curso e instituição. Vale ressaltar que alguns dos atributos elencados por Kotler e Fox (1994) e Murphy (1981) não foram incluídos no instrumento de coleta de dados, pois são compatíveis apenas com aspectos específicos da 
cultura e do comportamento norte-americanos. É o caso da moradia, pois na região do $\mathrm{ABC}$ Paulista não se reproduz a situação dos EUA, na qual a grande maioria dos alunos mora no campus. Como na região em estudo não existe esse hábito, também não foi preciso investigar a aparência física dos campi. Por outro lado, foi preciso considerar variáveis específicas da realidade local, como a segurança da região, a possibilidades de acesso e a posse de certificação da Fundação Getúlio Vargas.

$\mathrm{Na}$ fase descritiva, quando efetivamente se utilizou um instrumento de coleta, esse instrumento consistia num questionário elaborado a partir do resultado da fase exploratória, composto por quatro seções:

(1) Caracterização do estudante, do curso de nível médio e da família;

(2) Avaliação da importância dos motivos apresentados pela escolha do curso de Administração, atribuindo nota de zero a cinco para cada motivo; (3) Avaliação da importância dos motivos apresentados para a escolha da IES em que realiza o curso de Administração, atribuindo nota de zero a cinco;

(4) Informação aberta sobre aspectos complementares relativos à escolha do curso e da IES (outro curso superior cogitado; outra instituição para cursar Administração e motivo da escolha; instituições conhecidas, oferecendo Administração na região do ABC Paulista).

A validação do instrumento foi realizada pelo método de validação de conteúdo (ou validação facial), realizada por especialistas no conteúdo das métricas e na representatividade para a mensuração (KINNEAR; TAYLOR, 1996; NUNNALLY; BERNSTEIN, 1994; MALHOTRA, 2001), envolvendo quatro doutores em Administração, considerando uma base de 15 questionários respondidos a título de pré-teste.

A população da pesquisa é constituída por alunos recémingressantes no curso de Administração nas IES da região do ABC Paulista. No momento de realização da pesquisa, 18 instituições estavam estabelecidas e oferecendo cursos autorizados de graduação em Administração na região objeto de estudo, somando 9.340 vagas disponíveis. Seis dessas escolas de nível superior não ofereceram condições de acesso à pesquisa: Faculdades Octógono, pela ausência de turmas iniciantes há dois anos, e as outras cinco (Faculdade Anchieta, Faculdade de Diadema, Faculdade de São Bernardo, UniA e UNIBAN), não permitiram a realização de entrevistas. Desse modo, 12 instituições foram pesquisadas (Fundação Santo André, IMES, UniFEI, FIRP, 
Universidade Metodista, IESA, UNI ABC, FAENAC, FIA, Strong e Faculdade Tijucussú), compreendendo um total de 6.810 vagas, significando $73 \%$ do total de vagas no ABC Paulista. Em 2006, 3.145 alunos ingressaram nessas 12 instituições, sendo que a pesquisa foi aplicada pelo mesmo entrevistador da fase exploratória, nos espaços comuns no interior das instituições, em período próximo ao horário de aula, para 1.635 respondentes, representando $52 \%$ dos ingressantes.

Em função do problema de pesquisa, considerando-se a configuração do instrumento de coleta, formato, qualidade e quantidade de dados e, principalmente, os objetivos da investigação, a análise fatorial apresenta-se como uma alternativa consistente no estudo dos dados e adequada ao propósito deste trabalho. Segundo Hair et al (2005, p.91), a análise fatorial aborda a questão envolvida na análise de estrutura das inter-relações (correlações) "entre um grande número de variáveis... definindo um conjunto de dimensões latentes", os fatores, ou, como afirma Malhotra (2001), essa técnica multivariada objetiva a "reunião de proposições segundo a mesma tendência de correlação estatística, para se fazer julgamentos de aspectos que têm a mesma relevância frente ao conjunto de assertivas".

A amostragem, em função da limitação de acesso a parte do universo amostral, assim como a seleção dos entrevistados, realizada por disponibilidade, é não-probabilística. Entretanto, considerando a coleta de dados de $52 \%$ da população, admitiu-se a amostra relevante e qualificada para consideração dos resultados alcançados. Todavia, a generalização desses resultados não é possível, pela ausência de validade externa. Devem ser ainda ressalvados aspectos associados à adoção de escalas ordinais para variáveis métricas, por condições operacionais (faixa de renda do respondente e faixa de renda familiar), e, principalmente a utilização de médias, ao invés de medianas, como medidas de posição, que por esse motivo devem ser entendidas como estimativas aproximadas.

\section{Resultados da Pesquisa}

Os resultados obtidos na investigação são apresentados em quatro seções: 1) perfil dos estudantes, caracterizando a amostra abordada, 2) motivos intervenientes na escolha pela carreira de Administração, 3) motivos intervenientes na escolha pela IES e 4) estudo dos fatores relacionados à opção pela Administração e à decisão pela IES. 


\section{Perfil dos estudantes}

A média de idade dos alunos ingressantes é de 22 anos, variando de 17 a 52 anos, com um desvio padrão estimado de cinco anos. Os respondentes concluíram o ensino médio há quatro anos, em média, sugerindo interrupção nos estudos entre o segundo grau e o curso superior. A amostra apresenta $59 \%$ de mulheres e $41 \%$ de homens.

A maioria dos estudantes, $87 \%$ do total, é solteira, com $10 \%$ casados, $2 \%$ amasiados e $1 \%$ em outra situação (separados, viúvos ou divorciados). Dos entrevistados, $26 \%$ não trabalham; $74 \%$ trabalham, mesmo que parcial ou eventualmente, apresentando um rendimento médio de $\mathrm{R} \$ 818,50$. Entretanto, apenas $44 \%$ dos alunos são responsáveis integralmente pelo pagamento das mensalidades nos três primeiros meses do curso. $\mathrm{O}$ valor das mensalidades varia de $\mathrm{R} \$ 100,00$ a $\mathrm{R} \$ 888,00$, com média $\mathrm{R} \$ 507,20$ e desvio-padrão $\mathrm{R} \$$ 85,93. Esses valores são mais bem compreendidos quando se lembra que em 31/03/2006 o Diário Oficial da União publicou um novo valor para o salário-mínimo igual a $\mathrm{R} \$ 350,00$ e que nessa ocasião a cotação de venda do dólar americano oscilava em torno de $\mathrm{R} \$ 2,15$.

A amostra de estudantes entrevistados revela que $80 \%$ cursaram o ensino médio gratuito, contra $20 \%$ que estudaram em escolas particulares. Do total de entrevistados, $78 \%$ optaram pelo nível médio tradicional, sendo que daqueles que estudaram em cursos técnicos, $4 \%$ cursaram técnico em administração. Apenas $16 \%$ dos entrevistados fizeram cursos preparatórios para o vestibular.

\section{Motivos que influenciam a escolha pelo curso de Administração}

Com base nas respostas obtidas na fase exploratória, foi elaborada uma relação de motivos potencialmente influentes para a decisão pelo curso superior em Administração. $\mathrm{Na}$ fase descritiva, os estudantes entrevistados atribuíram notas a esses motivos, avaliando o grau de importância que eles apresentaram na sua escolha pessoal. A Tabela 2 reúne os resultados dessa avaliação realizada pelos entrevistados.

Verificou-se que $49 \%$ dos alunos estão no curso que desejavam, por informarem que não pensaram em seguir outra carreira. Entre aqueles que cogitaram outro curso observou-se importante dispersão nas respostas quando indagados sobre o curso alternativo. As áreas mais citadas foram Direito (5\%), Engenharia (5\%), Psicologia (4\%) e Publicidade e Propaganda (3\%). As duas razões mais frequentes para renunciarem a 
esses cursos foram: falta de condições financeiras (39\%) e preocupação com a empregabilidade após a conclusão (14\%).

Tabela 2: Grau de influência dos motivos na escolha do curso de Administração

\begin{tabular}{|c|c|c|c|c|c|c|c|c|c|}
\hline \multirow{2}{*}{ Motivo } & \multicolumn{7}{|c|}{ Frequência Absoluta } & \multirow{2}{*}{$\frac{\text { Média }}{\text { (estim.) }}$} & \multirow{2}{*}{$\begin{array}{l}\begin{array}{l}\text { Desvio } \\
\text { padrão }\end{array} \\
\text { (estim.) }\end{array}$} \\
\hline & $\mathbf{0}$ & 1 & 2 & 3 & 4 & 5 & Total & & \\
\hline $\begin{array}{l}\text { 1. Chances maiores de } \\
\text { emprego }\end{array}$ & 167 & 49 & 133 & 326 & 357 & 603 & 1635 & 3,5 & 2,6 \\
\hline 2. Salário & 279 & 120 & 280 & 427 & 278 & 251 & 1635 & 2,7 & 2,7 \\
\hline 3. Status da profissão & 374 & 127 & 261 & 337 & 249 & 287 & 1635 & 2,5 & 3,1 \\
\hline $\begin{array}{l}\text { 4. Afinidade com } \\
\text { disciplinas do ensino } \\
\text { médio }\end{array}$ & 480 & 120 & 213 & 313 & 198 & 311 & 1635 & 2,3 & 3,5 \\
\hline $\begin{array}{l}\text { 5. Crescimento no } \\
\text { emprego atual }\end{array}$ & 697 & 81 & 88 & 161 & 142 & 466 & 1635 & 2,2 & 4,7 \\
\hline $\begin{array}{l}\text { 6. Valor da } \\
\text { mensalidade }\end{array}$ & 687 & 161 & 215 & 241 & 137 & 194 & 1635 & 1,7 & 3,3 \\
\hline 7. Indicação da família & 714 & 166 & 235 & 215 & 119 & 186 & 1635 & 1,6 & 3,2 \\
\hline $\begin{array}{l}\text { 8. Negócio / profissão } \\
\text { dos pais }\end{array}$ & 1056 & 69 & 107 & 105 & 85 & 213 & 1635 & 1,2 & 3,5 \\
\hline $\begin{array}{l}\text { 9. Recomendação do } \\
\text { chefe }\end{array}$ & 1069 & 94 & 107 & 112 & 98 & 155 & 1635 & 1,1 & 3,0 \\
\hline $\begin{array}{l}\text { 10. Continuação do } \\
\text { curso técnico }\end{array}$ & 1177 & 62 & 61 & 61 & 79 & 195 & 1635 & 1,0 & 3,3 \\
\hline $\begin{array}{l}\text { 11. Orientação } \\
\text { vocacional }\end{array}$ & 1128 & 121 & 122 & 123 & 62 & 79 & 1635 & 0,8 & 2,2 \\
\hline 12. Vestibular fácil & 1166 & 146 & 156 & 102 & 62 & 53 & 1635 & 0,8 & 1,9 \\
\hline $\begin{array}{l}\text { 13. Professor modelo } \\
\text { no ensino médio }\end{array}$ & 1204 & 107 & 96 & 99 & 62 & 67 & 1635 & 0,7 & 2,0 \\
\hline $\begin{array}{l}\text { 14. Indicação de } \\
\text { professores no } 2^{\circ} \text { grau }\end{array}$ & 1296 & 121 & 101 & 62 & 27 & 28 & 1635 & 0,5 & 1,1 \\
\hline $\begin{array}{l}\text { 15. Gosto pelo tipo de } \\
\text { trabalho }\end{array}$ & 1594 & 1 & 2 & 1 & 1 & 36 & 1635 & 0,1 & 0,6 \\
\hline $\begin{array}{l}\text { 16. Afinidade com } \\
\text { atividades } \\
\text { administrativas }\end{array}$ & 1602 & 0 & 1 & 0 & 0 & 32 & 1635 & 0,1 & 0,5 \\
\hline $\begin{array}{l}\text { 17. Curso correto para } \\
\text { montar uma empresa }\end{array}$ & 1621 & 0 & 1 & 0 & 1 & 12 & 1635 & 0,0 & 0,2 \\
\hline $\begin{array}{l}\text { 18. Base para outras } \\
\text { profissões }\end{array}$ & 1623 & 0 & 1 & 1 & 1 & 9 & 1635 & 0,0 & 0,2 \\
\hline $\begin{array}{l}\text { 19. Aprendizado para } \\
\text { administrar a vida }\end{array}$ & 1625 & 0 & 1 & 1 & 0 & 8 & 1635 & 0,0 & 0,1 \\
\hline
\end{tabular}


Motivos que influenciam a escolha pela instituição para cursar Administração

Procedimento similar ao utilizado na investigação dos motivos que influenciam a escolha pelo curso de Administração foi realizado para a coleta de dados sobre os motivos para a escolha da instituição de ensino superior para cursar Administração.

Tabela 3: Grau de influência dos motivos na escolha da IES para cursar Administração

\begin{tabular}{|c|c|c|c|c|c|c|c|c|c|}
\hline \multirow{2}{*}{ Motivo } & \multicolumn{7}{|c|}{ Frequência Absoluta } & \multirow{2}{*}{$\begin{array}{c}\text { Média } \\
\text { (estim.) }\end{array}$} & \multirow{2}{*}{$\begin{array}{l}\text { Desvio } \\
\text { padrão } \\
\text { (estim.) }\end{array}$} \\
\hline & $\mathbf{0}$ & 1 & 2 & 3 & 4 & 5 & Total & & \\
\hline $\begin{array}{l}\text { 1. Conhecida como boa } \\
\text { escola }\end{array}$ & 130 & 37 & 137 & 292 & 348 & 691 & 1635 & 3,7 & 2,3 \\
\hline 2. Qualidade do ensino & 202 & 28 & 96 & 224 & 456 & 629 & 1635 & 3,6 & 2,7 \\
\hline $\begin{array}{l}\text { 3. Facilidade de acesso } \\
\text { (ir/voltar) }\end{array}$ & 215 & 69 & 168 & 222 & 276 & 685 & 1635 & 3,4 & 3,1 \\
\hline 4. Grade curricular & 311 & 78 & 197 & 324 & 357 & 368 & 1635 & 2,9 & 3,1 \\
\hline 5. Infra-estrutura & 362 & 95 & 229 & 315 & 256 & 348 & 1635 & 2,7 & 3,3 \\
\hline $\begin{array}{l}\text { 6. Valor da } \\
\text { mensalidade }\end{array}$ & 418 & 85 & 228 & 301 & 235 & 368 & 1635 & 2,6 & 3,5 \\
\hline $\begin{array}{l}\text { 7. Segurança (região e } \\
\text { acesso) }\end{array}$ & 486 & 112 & 235 & 331 & 215 & 256 & 1635 & 2,3 & 3,3 \\
\hline 8. Alunos recomendam & 544 & 86 & 200 & 303 & 217 & 285 & 1635 & 2,3 & 3,6 \\
\hline $\begin{array}{l}\text { 9. Mais mestres e } \\
\text { doutores }\end{array}$ & 558 & 105 & 158 & 315 & 259 & 240 & 1635 & 2,2 & 3,5 \\
\hline $\begin{array}{l}\text { 10. Facilidade de obter } \\
\text { emprego }\end{array}$ & 531 & 111 & 256 & 326 & 217 & 194 & 1635 & 2,1 & 3,2 \\
\hline $\begin{array}{l}\text { 11. Qualidade no } \\
\text { atendimento }\end{array}$ & 570 & 130 & 237 & 315 & 185 & 198 & 1635 & 2,0 & 3,2 \\
\hline $\begin{array}{l}\text { 12. Obteve boa nota no } \\
\text { provão }\end{array}$ & 693 & 90 & 165 & 225 & 190 & 272 & 1635 & 2,0 & 3,9 \\
\hline $\begin{array}{l}\text { 13. Família } \\
\text { recomendou }\end{array}$ & 699 & 96 & 195 & 227 & 169 & 249 & 1635 & 1,9 & 3,7 \\
\hline $\begin{array}{l}\text { 14. Amigos na } \\
\text { faculdade }\end{array}$ & 715 & 133 & 166 & 210 & 159 & 252 & 1635 & 1,8 & 3,7 \\
\hline $\begin{array}{l}\text { 15. Processo seletivo } \\
\text { fácil }\end{array}$ & 707 & 141 & 229 & 260 & 128 & 170 & 1635 & 1,7 & 3,1 \\
\hline $\begin{array}{l}\text { 16. Funcionários } \\
\text { recomendam }\end{array}$ & 1157 & 102 & 145 & 116 & 47 & 68 & 1635 & 0,8 & 2,0 \\
\hline $\begin{array}{l}\text { 17. Tem certificação } \\
\text { FGV }\end{array}$ & 1630 & 0 & 0 & 0 & 0 & 5 & 1635 & 0,0 & 0,1 \\
\hline
\end{tabular}

Com base nas respostas obtidas na fase exploratória foi elaborada uma relação de motivos potencialmente influentes para a decisão por uma determinada instituição de ensino. Nesse caso, os estudantes, assim como haviam realizado para a seleção da carreira universitária, atribuíram notas 
aos motivos apresentados, informando o grau de importância considerado sobre seu processo de escolha pessoal, na sua percepção. A Tabela 3 apresenta a tabulação dos dados coletados.

\section{Estudo dos fatores relacionados à opção pela Administração}

A investigação dos aspectos ou variáveis relevantes (intervenientes) foi desenvolvida por análise fatorial, em função do propósito orientado para a identificação de fatores (ou "conjunto de dimensões latentes", conforme Hair et al (2005, p.91). Nesse sentido, realizou-se o teste KMO, com resultado de 0,723 , considerado suficientemente elevado para indicar adequação dos dados para análise fatorial. $O$ teste de esfericidade de Bartlet, destinado a verificar a ausência de correlação entre as variáveis, apresentou significância inferior a 0,0001 (menor que 0,05), permitindo concluir presença de correlação entre variáveis, viabilizando a análise fatorial. A solução fatorial pode ser obtida por dois modelos básicos: análise de fatores comuns ou análise de componentes. A primeira, em função de condicionantes, como "desconhecimento anterior sobre variância específica e do erro", seria indicada a priori (HAIR et al, 2005, p.99). Entretanto, segundo os mesmos autores, "ela tem vários problemas", como indeterminância fatorial, suposições mais restritivas e maior demanda de recursos computacionais, entre outras limitações ao seu uso. Sobre essa questão, Hair et al (2005, p.99) afirmam:

[...] As complicações da análise de fatores comuns têm contribuído para o amplo uso da análise de componentes. Apesar de ainda haver muito debate sobre qual modelo fatorial é o mais apropriado, [...] na maioria das aplicações [...] chegam a resultados essencialmente idênticos se o número de variáveis exceder 30 ou se as comunalidades excederem 0,60 para a maioria das variáveis.

Nesse sentido, a opção por análise de componentes resultou da busca por uma solução de compromisso entre qualidade e utilidade de resultados versus funcionalidade e simplicidade do método. O número de fatores foi definido a partir do critério de normalização de Kaiser, considerado por Pestana e Gageiro (2000) adequado para amostras maiores que 250 sujeitos. Inicialmente, foram obtidos cinco fatores, respondendo por cerca de $52 \%$ da variância em relação ao traço da matriz fatorial, valor que "pode ser usado como um índice para determinar o quão bem uma solução fatorial particular explica o que todas as variáveis juntas representam" (HAIR et al, 2005, p.117), inferior a 60\%, como sugerido na mesma obra. Entretanto, esses autores observam que "se as 
variáveis são muito diferentes umas das outras, esse índice será baixo" (HAIR et al, 2005, p.117), oferecendo condição de admissão ressalvada do resultado. Procedeu-se a rotação fatorial, pelo método Varimax, orientada para uma "solução mais simples e pragmaticamente mais significativa" (HAIR et al, 2005, p.91). Para dimensões de amostra superiores a 250, a carga fatorial mínima significante é 0,35.

Tabela 4: Matriz dos Fatores Rotacionados e Comunalidades - Escolha do Curso de Administração

\begin{tabular}{|c|c|c|c|c|c|c|}
\hline \multirow{2}{*}{ Variável } & \multicolumn{5}{|c|}{ Fatores } & \multirow{2}{*}{ Comunalidade } \\
\hline & 1 & 2 & 3 & 4 & 5 & \\
\hline 1. Chances maiores de emprego & 0,804 & & & & & 0,658 \\
\hline 2. Salário & 0,765 & & & & & 0,638 \\
\hline 3. Status da profissão & 0,726 & & & & & 0,613 \\
\hline $\begin{array}{l}\text { 13. Professor modelo no ensino } \\
\text { médio }\end{array}$ & & 0,731 & & & & 0,586 \\
\hline 10. Continuação do curso técnico & & 0,686 & & & & 0,506 \\
\hline $\begin{array}{l}\text { 14. Indicação de professores no } \\
2^{\circ} \text { grau }\end{array}$ & & 0,567 & & & & 0,450 \\
\hline $\begin{array}{l}\text { 4. Afinidade com disciplinas do } \\
\text { ensino médio }\end{array}$ & & 0,562 & & & & 0,451 \\
\hline 11. Orientação vocacional & & 0,424 & & & & 0,315 \\
\hline 5. Crescimento no emprego atual & & & 0,849 & & & 0,725 \\
\hline 9. Recomendação do chefe & & & 0,828 & & & 0,711 \\
\hline 12. Vestibular fácil & & & & 0,780 & & 0,661 \\
\hline 6. Valor da mensalidade & & & & 0,772 & & 0,647 \\
\hline 7. Indicação da família & & & & & 0,749 & 0,619 \\
\hline 8. Negócio / profissão dos pais & & & & & 0,709 & 0,558 \\
\hline Autovalor & 1,76 & 1,82 & 1,41 & 1,20 & 1,06 & 7,26 \\
\hline Percentual da variância & 0,13 & 0,13 & 0,10 & 0,09 & 0,08 & 0,52 \\
\hline Alpha de Cronbach & 0,704 & 0,578 & 0,646 & 0,509 & 0,37 & \\
\hline $\begin{array}{l}\text { Indicador de Importância na } \\
\text { Escolha do Curso (IIEC) } \\
\end{array}$ & 2,9 & 1,1 & 1,7 & 1,3 & 1,4 & \\
\hline
\end{tabular}

Legenda: Fator 1 = Potencialidade da Carreira, Fator 2 = Afinidade com a Carreira, Fator $3=$ Continuidade de Carreira, Fator $4=$ Acessibilidade à Carreira e Fator $5=$ Familiaridade com a Carreira.

Nota1: Comunalidades - Método de Extração: Análise Fatorial de Componentes Principais.

Nota2: Indicador de importância na escolha foi calculado como média dos itens que compõem o fator (escala somada).

A Tabela 4 exibe a matriz dos fatores rotacionados e as variáveis que os compõem, sendo que as 14 variáveis consideradas derivam do elenco de 19 arroladas na fase exploratória. Cinco variáveis foram descartadas em função da baixa variabilidade manifestada, indicadas 
pelos valores de desvio-padrão expressos na Tabela 2, sugerindo influência nula dessas variáveis.

Da Tabela 4 depreende-se que o primeiro fator é composto pelas variáveis 1,2 e 3 , interpretado como Potencialidade da Carreira, estando associado à empregabilidade, à expectativa de remuneração e ao reconhecimento social. O segundo fator é composto pelas variáveis 13, 10, 14, 4 e 11, tratado por Afinidade com a Carreira, envolvendo identidade com a administração, imagem do curso e concepção associada a experiências ligadas à carreira. $\mathrm{O}$ terceiro fator é representado pelas variáveis 5 e 9, chamado de Continuidade de Carreira e indica um apelo mais pragmático ao desenvolvimento pessoal, baseado na condição presente. As variáveis 12 e 6 compõem o quarto fator, identificado como Acessibilidade à Carreira, devido à sua ligação com viabilidade favorecida de cursar Administração. O quinto fator é composto pelas variáveis 7 e 8, entendido como Familiaridade com a Carreira, por se vincular a estímulo afetivo ou contato prévio com atividades afeitas à Administração.

A Tabela 4 apresenta o valor de Alpha de Cronbach como indicador de confiabilidade para cada um dos fatores, "sendo os valores de 0,60 a 0,70 considerados o limite inferior de aceitabilidade", segundo Hair et al (2005, p.90). O primeiro fator está associado a um Alpha de Cronbach 0,704, o segundo fator a 0,578, o terceiro fator a 0,646, o quarto fator a 0,509 e o quinto fator a 0,370. Os resultados sugerem aceitabilidade para os três primeiros fatores.

Um aspecto de relevância para a admissão dos resultados se constitui na avaliação da qualidade de representação e síntese que cada fator possui em relação às variáveis que incorpora, conforme Pasquali (2003). O exame das comunalidades, que indicam a fração da variância da variável explicada pelo fator que a representa, foi utilizado com esse objetivo. Baseando-se na prescrição de Hair et al (2005, p.108), que considera a necessidade de uma especificação do pesquisador sobre "fração de variância das variáveis que deve ser levada em conta", adotouse $50 \%(0,5)$, sendo que variáveis com comunalidades menores que 0,50 não teriam explicação suficiente. Analisou-se o rol de variáveis utilizadas, cujo resultado encontra-se na última coluna da Tabela 4. As variáveis 4, 11 e 14 apresentam os menores valores de comunalidade, apresentando as menores correlações com os fatores, sendo que a variável 11 teria de ser ressalvada, por não ter explicação suficiente.

Adicionalmente, optou-se por se arbitrar um parâmetro, orientado para a avaliação exploratória da relevância de cada fator na escolha do 
curso. Esse parâmetro, batizado como Indicador de Importância na Escolha do Curso (IIEC), resultou da média dos valores de Grau de Influência das variáveis, que compunham cada fator. Considerando a escala ordinal utilizada (0-1-2-3-4-5), a apreciação do IEEC dos cinco fatores sugere que a influência do fator Potencialidade de Carreira tende a ser decisiva para a seleção do curso, enquanto os demais fatores assumem o papel de coadjuvantes nessa decisão.

\section{Estudo dos fatores relacionados à escolha da Instituição}

O procedimento foi conduzido de forma semelhante ao anterior. O teste KMO resultou no valor 0,871 , indicando adequação dos dados para a análise fatorial. $\mathrm{O}$ teste de esfericidade de Bartlet apresentou significância menor que 0,0001 , o que permite concluir a presença de correlação entre as variáveis. A quantidade de fatores baseou-se no critério de Kaiser, para a rotação foi usado o método Varimax e corte da carga fatorial adotado em 0,35 , mantendo a consistência com o procedimento anterior. A variância explicada pelos cinco fatores considerados é de cerca de $45 \%$ da variância associada ao traço da matriz fatorial, indicador que remete a potenciais ressalvas em relação à validade da aproximação desenvolvida, conforme discutido para a escolha de carreira. A variável 17 foi descartada em função do resultado expresso na Tabela 3, que sugere influência nula sobre a escolha da IES.

A Tabela 5 exibe a matriz dos fatores rotacionados, identificando as variáveis representadas em cada fator. Nessa tabela observa-se que o primeiro fator é composto pelas variáveis $4,5,7,9$, e 11 , identificado como Infra-estrutura da Instituição; o segundo fator é composto pelas variáveis 1, 2, 10, 12 e 13, tratado por Imagem da Instituição; o terceiro fator é composto pelas variáveis 8,14 e 16, denominado Indicação da Instituição; as variáveis 6 e 15 compõem o quarto fator, entendido como Instituição Acessível. O quinto fator é composto unicamente pela variável três, podendo ser entendido pelo sentido da própria variável, ou seja, Facilidade de Transporte. Note-se que variáveis consideradas relevantes para ambas as abordagens e que estão associadas a um dado fator para um dos modelos (Escolha de Carreira e Escolha de IES) não necessariamente se apresentam agrupadas para o outro modelo.

Pela tabela 5, pode-se constatar que o valor de Alpha para o primeiro fator é 0,795 , para o segundo fator é 0,712 , para o terceiro fator é 0,642 , para o quarto fator é 0,352 , indicando que a consistência interna é admissível para os três primeiros fatores. O cálculo das comunalidades, 
adotando prática idêntica à conduzida para opção do curso de Administração, é apresentado na última coluna à direita da Tabela 5.

A Tabela 5 indica que as variáveis possuem comunalidades acima de 0,5 , indicando uma correlação aceitável com fatores obtidos. Os resultados indicam que aspectos estruturais explicam, isoladamente, $30,7 \%$ da variância dos dados.

Tabela 5: Matriz dos Fatores Rotacionados e Comunalidades - Escolha da IES

\begin{tabular}{|c|c|c|c|c|c|c|}
\hline \multirow{2}{*}{ Variável } & \multicolumn{5}{|c|}{ Fatores } & \multirow{2}{*}{ Comunalidade } \\
\hline & 1 & 2 & 3 & 4 & 5 & \\
\hline 5. Infra-estrutura & 0,776 & & & & & 0,638 \\
\hline 7. Segurança (região e acesso) & 0,739 & & & & & 0,639 \\
\hline 4. Grade curricular & 0,712 & & & & & 0,587 \\
\hline 11. Qualidade no atendimento & 0,640 & & & & & 0,549 \\
\hline 9. Mais mestres e doutores & 0,517 & & & & & 0,516 \\
\hline 1. Conhecida como boa escola & & 0,735 & & & & 0,707 \\
\hline 13. Família recomendou & & 0,602 & & & & 0,506 \\
\hline 12. Obteve boa nota no provão & & 0,599 & & & & 0,618 \\
\hline 10. Facilidade de obter emprego & & 0,572 & & & & 0,510 \\
\hline 2. Qualidade do ensino & & 0,565 & & & & 0,632 \\
\hline 14. Amigos na faculdade & & & 0,715 & & & 0,632 \\
\hline 16. Funcionários recomendam & & & 0,656 & & & 0,593 \\
\hline 8. Alunos recomendam & & & 0,634 & & & 0,593 \\
\hline 15. Processo seletivo fácil & & & & 0,741 & & 0,642 \\
\hline 6. Valor da mensalidade & & & & 0,590 & & 0,687 \\
\hline 3. Facilidade de acesso (ir/voltar) & & & & & 0,827 & 0,734 \\
\hline Autovalor & 2,33 & 1,91 & 1,34 & 0,90 & 0,68 & 7,16 \\
\hline Percentual da variância & 0,15 & 0,12 & 0,08 & 0,06 & 0,04 & 0,45 \\
\hline Alpha de Cronbrach & 0,795 & 0,712 & 0,642 & 0,352 & ---- & \\
\hline $\begin{array}{l}\text { Indicador de Importância na } \\
\text { Escolha da Instituição (IIEI) }\end{array}$ & 2,4 & 2,3 & 1,6 & 2,2 & 3,4 & \\
\hline
\end{tabular}

Legenda: Fator 1 = Infra-estrutura da Instituição, Fator 2 = Imagem da Instituição, Fator 3 = Indicação da Instituição, Fator 4 = Instituição Acessível e Fator 5 = Facilidade de Transporte.

Nota1: Comunalidades - Método de Extração: Análise Fatorial de Componentes Principais.

Nota2: Indicador de importância na escolha foi calculado como média dos itens que compõem o fator (escala somada). 
Da mesma forma que se adotou o parâmetro IEEC, construiu-se o Indicador de Importância na Escolha da Instituição (IEEI), como média dos valores de Grau de Influência das variáveis, que compunham cada fator. $\mathrm{Na}$ avaliação do IEEI dos cinco fatores na Tabela 5, observa-se que quatro destes são de relevância apreciável para a decisão de IES, sobressaindo-se entre estes quatro o fator facilidade de transporte.

\section{CONCLUSões}

Conclui-se, considerando as limitações da pesquisa, que a escolha do curso de Administração compreende cinco dimensões: potencialidade, afinidade, continuidade, acessibilidade e familiaridade com a carreira, sendo que potencialidade, envolvendo empregabilidade, expectativa de remuneração e reconhecimento social, apresenta-se como principal condicionante da opção. A escolha de uma instituição considera, conforme o estudo, cinco fatores: infra-estrutura, imagem, indicação, instituição acessível e facilidade de transporte. De todos os cinco fatores, apenas o fator instituição acessível apresenta reduzida influência na escolha da IES. Dos demais fatores, todos de influência relevante para escolha de IES, por ordem crescente de importância revelaram-se: indicação, imagem, infra-estrutura e facilidade de transporte. Cabe ainda ressaltar que facilidade de transporte apresenta diferença significativa de importância em relação aos demais.

Comparando-se os atributos considerados pelos estudantes dos EUA para a escolha do curso universitário, apresentados por Kotler e Fox (1994) e Murphy (1981), com os fatores que afetam a escolha da carreira de administração e da IES para a realização do curso (tabelas 4 e 5), é possível observar que o primeiro dos atributos americanos é justamente aquele em que se pode perceber com mais facilidade uma ligação com os fatores obtidos a partir das respostas dos alunos do ABC Paulista. De fato, esse atributo, a reputação acadêmica, no caso brasileiro pode ser associada ao fator imagem da IES, o segundo em termos de colaboração para explicação da variância total, com o valor 0,12 . O segundo atributo americano, por ordem de apresentação, o custo da mensalidade, no caso brasileiro pode ser ligado aos fatores acessibilidade à carreira e instituição acessível. Entretanto, vale observar que a colaboração desses fatores para a explicação da variância total não é alta, apenas 0,09 e 0,06, respectivamente. $\mathrm{O}$ atributo colocação no mercado de trabalho, o último lembrado pelos autores americanos, é similar, no caso nacional, ao fator 
potencialidade da carreira, o que mais contribui $(0,13)$ para a explicação da variância na escolha do curso de Administração. Os demais atributos listados por Kotler e Fox (1994) e Murphy (1981), provavelmente por serem muito ligados à realidade dos Estados Unidos, guardam pouca relação com as respostas obtidas no ABC Paulista. Por fim, pode ser interessante observar que os fatores com maior percentual de explicação da variância nas tabelas 4 e 5 sugerem que os estudantes do ABC Paulista têm preocupações práticas com a condução de suas vidas profissionais (vide os fatores potencialidade da carreira com percentual da variância igual a 0,13 e continuidade da carreira, com 0,10) e que, em consequência, na escolha da IES consideram aquelas que têm mais condições de corresponder a esses anseios, combinando-se a aspectos de praticidade no cotidiano (vide a importância dos fatores facilidade de transporte, infra-estrutura, imagem e indicação da IES).

Esta pesquisa ajuda na compreensão do processo de decisão do curso superior e da escolha da faculdade pelos alunos do ABC Paulista, uma região que, apesar de sua expressão econômica e elevados índices de qualidade de vida, em especial, no caso de São Caetano, ainda é carente de informações a esse respeito. Além disso, em estudos futuros, as informações obtidas nesse contorno geográfico e temporal podem ser comparadas com as de outras regiões ou datas, de forma a se ter uma ideia da dinâmica dessas decisões. Do ponto de vista do mercado, o presente trabalho remete à focalização de estratégias de IES orientadas para o mercado de egressos do ensino médio. Apelos em relação ao curso de Administração associados à expectativa ou à existência de programas específicos de colocação profissional, assim como ao acesso a remunerações compensadoras e reconhecimento social, poderiam ser temas de comunicação. Para divulgação da instituição como meio de acesso ao ensino superior, a comunicação prioritariamente deveria enfatizar os diferenciais que a IES possua, vinculados à facilidade de transporte, estrutura e qualidade da instituição.

\section{REFERÊNCIAS}

ALBRECHT, K. Revolução dos serviços: Como as empresas podem revolucionar a maneira de tratar os seus clientes. São Paulo: Pioneira, 1992.

ARAUJO, S. P. M. Motivos que influenciam a escolha do curso e carreira de administração e da instituição de ensino superior: um estudo 
sobre os alunos de administração na região do Grande ABC. São Paulo, 2006. Dissertação. Programa de Mestrado em Administração.

Universidade Cidade de São Paulo.

BATESON, J. E. G.; HOFFMAN, K. D. Marketing de serviços. 4. ed. São Paulo: Artmed, 2001.

BLAU, P. M.; GUSTAD, J.W.; JESSOR, R.; PARNES, H.S.; WILCOCK, R.C. Occupational choice: A conceptual framework. In: ZYTOWSKI, D. G. (Org.) Vocational behavior: Reading in theory and research. New York: Holt, Rinehart and Winston, 1968, p.358-370.

BOMTEMPO, M. S.; SILVA, D.; GARCIA, M. N.; CODA, R. Estudo dos Motivos da Escolha do Curso de Administração de Empresa por meio da Modelagem de Equação Estruturais. In: XXXI Encontro Nacional dos Programas de Pós-Graduação em Administração - EnANPAD, 2007, Rio de Janeiro. Anais... Rio de Janeiro: Anpad, 2007.

CARVALHO, B. G.; BERBEL, M. C. Marketing educacional. São Paulo: Alabama, 2000.

CHANLAT, J. F. Quais carreiras e para qual sociedade? Revista de Administração de Empresas, v. 35, n. 6, p. 67-75, 1995.

CRITES, J. O. Psicologia vocacional. Buenos Aires: Editorial Paidos, 1974.

ENGEL, J. F.; BLACKWELL, R. D.; MINIARD, P. W. Comportamento do Consumidor. São Paulo: LTC, 2001.

ESPARTEL, L. B.; TREZ, G.; FONSECA, M. J. A mensuração do envolvimento do aluno de administração com o curso como instrumento de melhoria da qualidade de ensino. In: XXV Encontro Nacional dos Programas de Pós-Graduação em Administração - EnANPAD, 2001, Campinas. Anais... Campinas: Anpad, 2001.

FOLMER-JOHNSON, M. C. Projeto pessoal de vida \& trabalho: A orientação profissional na perspectiva de orientadores e orientandos. Dissertação de Mestrado. Faculdade de Educação, Universidade Estadual de Campinas - UNICAMP, Campinas-SP, 2000.

GODOY, A. S.; SANTOS, F. C. dos; MOURA, J. A. de. Avaliação do impacto dos anos de graduação sobre os alunos: estudo exploratório com estudantes do último ano dos cursos de Ciências Contábeis e Administração de uma faculdade particular de São Paulo. Revista Administração On Line, São Paulo, v. 2, n. 1, 2001. 
GORDON, W.; LANGMAID, R. Contemporary Qualitative Market Research. Hampshire: Gower Publishing Limited, 1988.

HAIR, J. F.; ANDERSON, R. E.; TATHAM, R. L.; BLACK, W. C. Análise multivariada de dados. Porto Alegre: Bookman, 2005.

HOFFMAN, K. D. Princípios de Marketing de Serviços: Conceitos, Estratégias e Casos. São Paulo: Thomson Learning, 2003.

HOLLAND, J. L. Técnica de la elección vocacional: tipos de personalidad y modelos ambientales. México: Trillas, 1975.

IHLANFELDT, W. Achieving optimal enrollments and tuition revenues. San Francisco: Jossey-Bass, 1980.

INEP - Instituto Nacional de Estudos e Pesquisas Educacionais Anísio Teixeira. Censo da Educação Superior: Informações sobre IES. Disponível em: <http://www.inep.gov.br/superior/censosuperior /default.asp>. Acessado em: 20/07/2006.

INEP - Instituto Nacional de Estudos e Pesquisas Educacionais Anísio Teixeira. Estudos, pesquisas e avaliação sobre o sistema educacional brasileiro. Disponível em: 〈http://www.inep.gov.br>. Acessado em: 20/01/2006.

JACOB, J.; KAPLAN, L.B. The components of perceived risks. In: Proceedings of the Third Annual Conference of the Association for Consumer Research, p.382-393, 1972.

KINNEAR, T. C.; TAYLOR, J. R. Marketing research: An applied approach. 5.ed. New York: McGraw-Hill, 1996.

KOTLER, P.; FOX, K. F. Marketing estratégico para instituições educacionais. São Paulo: Atlas, 1994.

LOVELOCK, C.; WIRTZ, J. Marketing de Serviços. 5 ed. São Paulo: Prentice-Hall, 2006.

MALHOTRA, N. K. Pesquisa de marketing: Uma orientação aplicada. 3.ed. Porto Alegre: Bookman, 2001.

MORAES, E. A.; GRAEML, A. R.; SANCHEZ, O. P.; MESQUITA, F. S. B. Seleção de cursos de educação continuada por executivos de empresas. Revista de Administração de Empresas Eletrônica, v. 5, n. 2, art. 13, 2006. 
MURPHY, P. E. Consumer buying roles in college choice: Parents' and students' perceptions. College and University, v. 57, p. 150-160, 1981.

NUNNALLY, J.C.; BERNSTEIN, I.H. Psychometric Theory. 3.ed. New York: McGraw-Hill, 1994.

OLIVEIRA, G. Saudoso Provão. Folha de São Paulo, S. Paulo, 15/05/2004. Disponível em:

<http://www1.folha.uol.com.br/folha/gesneroliveira/

FSP/2004/05_2004/150504.htm>. Acessado em: 19/08/2006.

OLIVEIRA, L. R. Estudo do projeto de vida profissional de alunos universitários do curso de pedagogia. Dissertação de Mestrado. Faculdade de Educação, Universidade Estadual de Campinas UNICAMP, Campinas-SP, 2001.

PASQUALI, L. Psicometria: Teoria dos testes na psicologia e na educação. Petrópolis: Vozes, 2003.

PESTANA, M. H.; GAGEIRO, J. N. Análise de dados para ciências sociais: A complementariedade do SPSS. 2.ed. Lisboa: Silabo, 2000.

PIMENTA, S. G. Orientação vocacional e decisão: Estudo crítico da situação no Brasil. São Paulo: Edições Loyola, 1979.

PLATÃO. Apologia a Sócrates. Trad. Carlos Alberto Nunes. Belém do Pará: Universidade Federal do Pará, 1980.

SHETH, J.; MITTAL, B.; NEWMAN, B. I. Comportamento do Cliente: Indo Além do Comportamento do Consumidor. São Paulo: Atlas, 2001.

SILVA, W. R.; MACHADO, M. A. V. Motivos que Levam os Alunos a Cursar Graduação em Administração: Uma análise comparativa entre instituições públicas e privadas do estado da Paraíba. Revista de Administração Mackenzie, v. 8, n. 4, p. 125-152, 2007.

SINGER, P. A universidade no olho do furacão. In: Dossiê Educação. Estudos Avançados. Universidade de São Paulo, Instituto de Estudos Avançados, v.15, n.142, p.305-316, 2001.

SOARES-LUCCHIARI, D. H. P. O jovem e a escolha profissional. Porto Alegre: Mercado Aberto, 1987.

SUPER, D. E.; BOHN JR., M. J. Psicologia ocupacional. São Paulo: Atlas, 1980. 
TERENCE, A. C. F.; ESCRIVÃO F. E. Abordagem quantitativa, qualitativa e a utilização de pesquisa-ação. In: XXVI Encontro Nacional de Engenharia de Produção - ENEGEP, 2006, Fortaleza. Anais...Fortaleza:ABEPRO, 2006.

WHITAKER, D. A escolha da carreira. São Paulo: Moderna, 1985.

ZEITHAML, V.; BITNER, M. J. Marketing de Serviços: A empresa com foco no cliente. 2.ed. São Paulo: Bookman, 2003. 


\section{DAdOS DOS AUTORES}

Sergio Paulo Muniz de Araujo (sergiopaulo3@uol.com.br)

Mestre em Administração de Empresas pela Universidade Cidade de São Paulo

Instituição de vinculação: Escola Superior de Administração e Gestão Santo André/SP - Brasil

Áreas de interesse em pesquisa: Estratégia.

JoÃo MaUrício GAMA BoAVEnTURA (jm @ boaventura.adm.br)

Doutor em Administração de Empresas pela FEA/USP

Instituição de vinculação: Faculdade de Economia, Administração e Contabilidade da Universidade de São Paulo

São Paulo/SP - Brasil

Áreas de interesse em pesquisa: Estratégia e Ensino Superior.

RENATO TELLES (rtelles@usp.br)

Doutor em Administração de Empresas pela FEA/USP

Instituição de vinculação: Universidade de São Caetano do Sul

São Caetano do Sul/SP - Brasil

Áreas de interesse em pesquisa: Marketing e Estratégia.

João Paulo Lara de Siqueira (siqueira.jp@uol.com.br)

Doutor em Administração de Empresas pela FEA/USP

Instituição de vinculação: Universidade Paulista - Programa de Mestrado em Administração

São Paulo/SP - Brasil

Áreas de interesse em pesquisa: Estratégia, Rede de Negócios e Ensino Superior.

ANDRÉ RICARDo RobIC (andre @ibmoda.com.br)

Doutor em Administração de Empresas pela FEA/USP

Instituição de vinculação: Fundação Armando Álvares Penteado e Instituto Brasileiro de Moda

São Paulo/SP - Brasil

Áreas de interesse em pesquisa: Marketing e Estratégia.

Recebido em: 17/09/2009 • Aprovado em: 28/06/2010 